\title{
Energy Resource Management Model in a Hotel Building Using a Web Platform
}

\author{
Tiago Sousa, Pedro Faria, Zita Vale \\ GECAD - Research Group on Intelligent Engineering and \\ Computing for Advanced Innovation and Development \\ IPP - Polytechnic Institute of Porto \\ Porto, Portugal \\ \{tabsa,pnfar, zav\}@isep.ipp.pt
}

\author{
Jorge Landeck, Luísa Matos, Rodrigo Ferreira \\ VPS - Virtual Power Solutions \\ Coimbra, Portugal \\ \{jlandeck, lmatos, rferreira\}@vps.energy
}

\begin{abstract}
Distributed generation and demand response have been fostered in the last years, sometimes less than desired. In fact, these energy resources, which have a distributed nature have been mostly applied and discussed in the wide view of the operation and planning of the distribution system. However, a great potential is now being explored in the scope of buildings energy management. In the present paper, an energy resource management model has been implemented in order to be integrated with a web platform that supports the customer information concerning energy usage. The model can be used for several kinds of buildings. A hotel building is focused in this paper, namely in the case study that discusses the use of each resource, including photovoltaic generation and demand response.
\end{abstract}

Keywords-Demand response, distributed distributed energy resource scheduling, hotel building I. INTRODUCTION

Whether they include domestic, commercial, or services consumers, buildings represent the largest energy-consuming sector in the economy, with over one-third of all final energy and half of global electricity consumed there [1]. The concerns about energy efficiency and sustainability have been addressed in the last years in the scope of smart grids [2]. Important resources include Demand Response (DR) and Distributed Generation (DG). Concerning DR, several programs have been implemented for the participation of consumers in situations of high market prices and low reliability of operation. Further work must be done in order to take the full potential of the small size consumers, as the domestic, commercial, and services ones [3]. In the DG side, a large use of wind generation has been achieved. However, in the buildings point of view, the most advantageous one is the Photovoltaics (PV) generation [4].

Currently, there is a wide range of commercial solutions for the energy management of the resources available in a service building (e.g. airports, malls and public buildings). These solutions consider a variety of functionalities since monitoring, control and data acquisition, nevertheless, they lack in considering an intelligent approach for an adequate energy resources management. This intelligent approach can be accomplished by applying optimization methodologies for the energy resource management. Therefore, an optimization

The present work has received funding under the AVIGAE Project (P2020 - 3401), and from FEDER Funds through COMPETE program and from National Funds through FCT under the project UID/EEA/00760/2013. methodology for the energy resource management published in [5], [6] is implemented in the Kisense ${ }^{\circledR}$ tool (http://www.vps.energy/solutions-kisense), provided by VPSC Company. This methodology will help to optimally manage the resources in a certain service building taking into account a specific goal (e.g. minimizing the cost or maximizing the profit).

The VPS commercial platform developed for the energy resource management of service buildings - Kisense - allows real-time analyses and monitoring of energy consumption data. Easy and quick decision making concerning energy management can be achieved. The main motivation is that the user doesn't need to be an energy management expert to use this platform. In fact, it provides tools for distinct levels of expertise. The user can easily find means of achieving energy savings and costs reduction.

This paper uses the novel methodology in [5], [6] to optimally schedule the resources of a hotel (i.e. service building) considering the most recent forecast of the resources. The main idea of this paper is to test the importance of optimization methodologies in commercial platform, such as the one presented by the VPS Company. In particular, to validate if the optimization methodology published in [5], [6] can represent a valid option to be incorporated in a commercial platform

A Portuguese Hotel is used as case study of this paper. The hotel used in this paper is constituted by distributed resources to partially support the energy consumption of the building, where most of them are based on renewable sources. There is also a connection with the electric network that enables to acquire energy from external entities (e.g. bilateral contracts, service providers, etc). Additionally, the hotel can also take into account demand response programs, through direct load control, implemented in several equipment, which enables the decrease of energy consumption instead of using expensive generation resources.

The paper will be divided by four sections, where the introductory part is presented in Section I. The optimization methodologies used in this paper is presented in Section II. The case study which exposes the results of the energy resource management in the Hotel is presented in Section III. The main conclusions of this paper are indicated in Section IV. 


\section{Energy Resource MANAGEMEnt Model}

The aggregator player has the purpose to obtain the best scheduling of the resources through an Energy Resource Management (ERM) model [7]. The ERM model can be a main challenge in the context of a large penetration of distributed resources in the network [8]. The same is applied to a service building with a large set of distributed resources operating in the building. Therefore, the aggregator players of resources require to use new strategies to well manage under a scenario with intensive use of distributed resources [9]. This paper uses the ERM model presented in [5], [6] to be applied in the scheduling of a service building (i.e. Hotel). Fig. 1 depicts the architecture of the platform associated with the ERM model used in this paper.
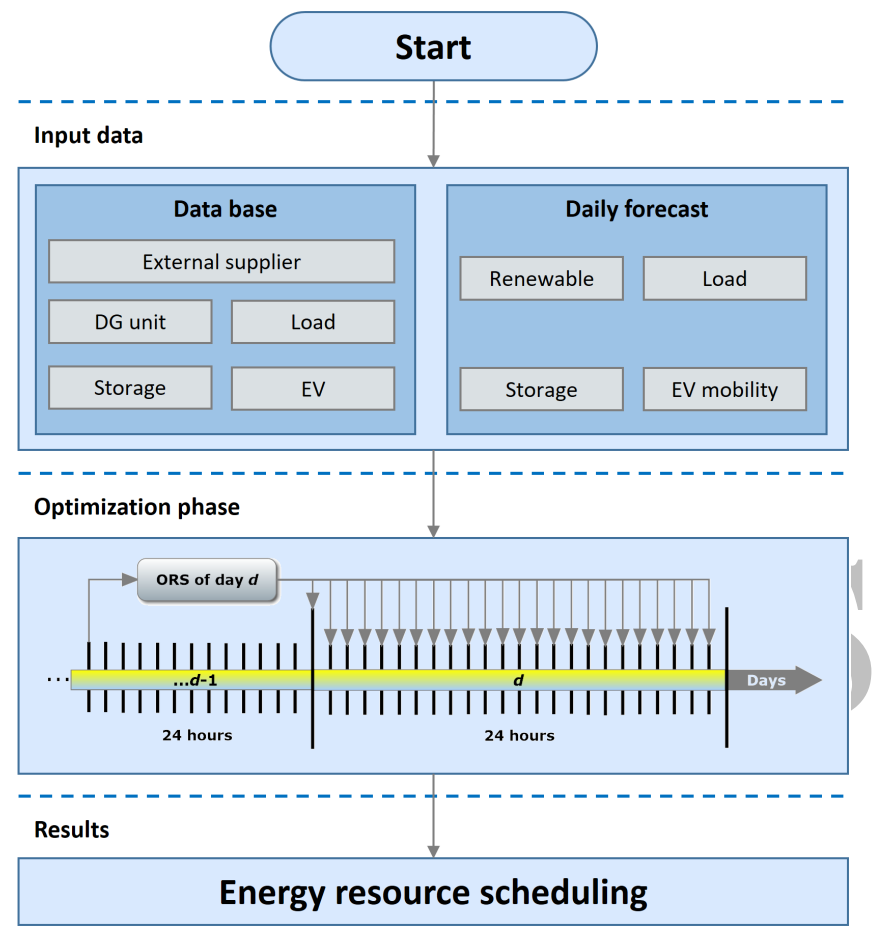

Fig. 1. ERM simulation platform

The ERM simulation platform proposed in [5], [6] considers 3 different time-horizons, namely day-ahead, hourahead and real-time. In this paper, the time-horizon of the dayahead is used, i.e. scheduling for the next day. The ERM platform can consider different objective functions depending on the point of view defined by the aggregator. This platform can consider the profits maximum or the cost minimization.

The ERM platform starts by considering the input data for the ERM model. The input data has two sources, first comes from the data base that contains all important information related with type of resource, and second is concerned to the daily forecast which is necessary to have from the consumption and resources with intermittent behavior (e.g. renewables and Electric Vehicles (EVs)). For instance, the daily forecast of the expected power generation from renewable sources, such as wind and solar. The forecast related with EVs is also considered, for instance, the number of EVs parked in the hotel and the expected energy spent with EVs trips.

\section{A. Mathematical Formulation}

The ERM model minimizes the operation cost $(C)$ of an aggregator that is given by

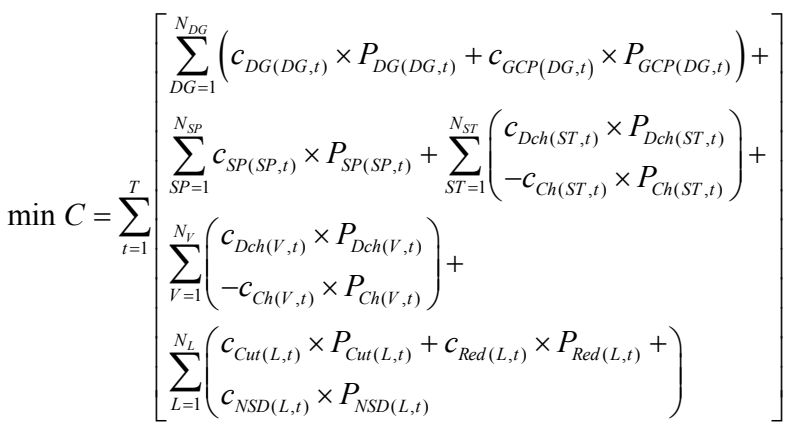

where $c_{D G(D G, t)}$ and $P_{D G(D G, t)}$ stand for the energy price and scheduled power of each DG unit, respectively. $c_{G C P(D G, t)}$ and $P_{G C P(D G, t)}$ correspond to the compensation and price and power generation curtailment of each DG unit, respectively. More precisely, the DG units based on intermittent renewable sources (e.g. wind and solar) are fully dispatched by the aggregator. However, if these DG units presents a surplus of power generation, the surplus is curtailed $\left(P_{G C P(D G, t)}\right)$ and the DG is remunerated by the aggregator player $\left(c_{G C P(D G, t)}\right) . N_{D G}$ refers to the total number of DG units.

The terms $c_{S P(S P, t)}$ and $P_{S P(S P, t)}$ are the energy price and the amount of power to acquire from each external supplier $S P$ that is outside of the service building. The aggregator can also consider storage systems to balance the scheduling of the service building, where in (1) takes into account the charge and discharge processes. $P_{C h(S T, t)}$ and $P_{D c h(S T, t)}$ are the scheduled power for the charge and discharge, respectively. Both processes have an energy price associated $\left(c_{C h(S T, t)}\right.$ and $\left.c_{D c h(S T, t)}\right)$ for the energy price and scheduled power of each DG unit, respectively. The total number of external suppliers and storage devices are indicated by $N_{S P}$ and $N_{S T}$, respectively.

The service building (e.g. hotel) can also receive EVs, which can plug into the service building network to charge their batteries or to participate in the scheduling through V2G. Thus, in (1) uses the same variables and parameters to represent the charge and discharge processes of EVs as it is used for the storage systems. The aggregator can also activate some DR programs to improve the ERM solution. The building has two type of DR programs, the load curtailment represented by $P_{C u t(L, t)}$ and the load reduction represented by $P_{\operatorname{Red}(L, t)}$. Both DR programs have an associated price $\left(c_{C u t(L, t)}\right.$ and $\left.c_{\operatorname{Red}(L, t)}\right)$. Finally, if the aggregator does not have enough power generation to supply the power demand, some of the demand is not supplied. This is represented by the variable $P_{N S D(L, t)}$ and it has an associated compensation $\left(c_{N S D(L, t)}\right)$ that aggregator must pay to the service building. 
This optimization problem is formulated as mixed-integer linear programming problem. The ERM model considers the power capacity of all available resources, energy stored in the batteries of storage systems and EVs, and DR power limits. A detailed explanation concerning these constraints can be seen in [5].

\section{CASE STUdy}

The present case study takes into account a Portuguese Hotel, where the ERM is determined by an aggregator. The main goal is to obtain the minimum operation cost (1) while supplying the required demand of the different equipment in the Hotel. The case study uses data collected from the Hotel and adapted data from other measurements (e.g. residential houses, restaurants, bars, and so on).

The simulations were developed in MATLAB R2012a 32 bits and in GAMS 22.932 bits software. The case study in this paper has been tested in a machine with two processors Intel ${ }^{\circledR}$ Xeon ${ }^{\circledR}$ E5-2620 v2 $2.10 \mathrm{GHz}$, each one with two cores, 16GB of random-access-memory and Windows 8.1 Professional 64 bits operating system.

This case study section is divided into three sub-sections. Sub-section IV.A presents the description of the resources that compose the Hotel. Sub-section IV.B explains the different scenarios developed for this case study. Finally, the results and analysis are presented in sub-section IV.C.

\section{A. Resources Description}

The resources and scenarios developed for this case study are referred to the year 2016, and the hotel is constituted by the following equipment: chillers 1 and 2, central kitchen, SPA with an air conditioner, external and internal pools, administrative services, 4 restaurants, 4 bars, 20 conference rooms, 5 elevators, 5 photovoltaic (PV) panels and 377 rooms. The 377 rooms are divided in 338 normal rooms, 18 junior suites, 20 suites and 1 presidential suite. For this case study, the energy consumption at $3^{\text {rd }}$ of September of 2015 is used, which is illustrated in Fig. 2.

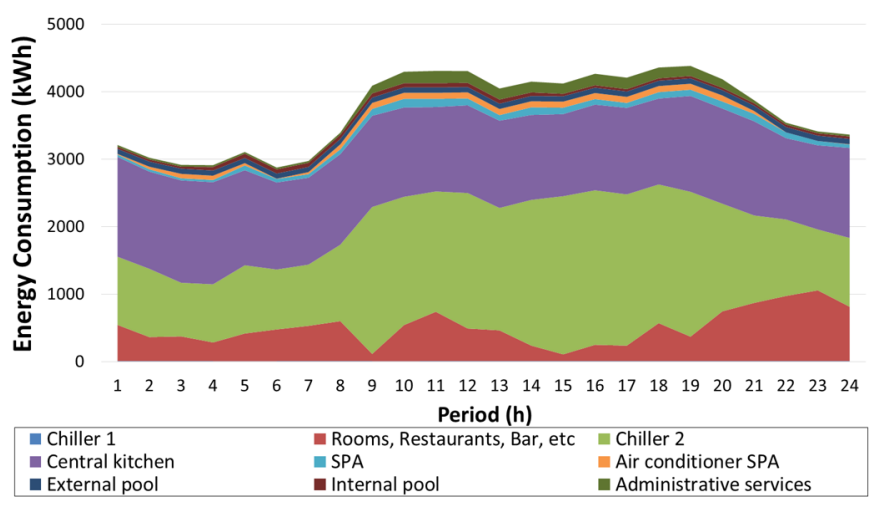

Fig. 2. Hotel energy consumption of day $3^{\text {rd }}$ of September of 2015.

Analyzing Fig. 2, the 'Chiller 2' and 'Central kitchen' represent most of the consumption, each one reaches around $41 \%$ and $36 \%$ of the all consumption, respectively. The aggregator can two DR programs, which are direct load control programs, in all the loads instead of the rooms of the hotel. The DR reduce and cut programs can be applied for $20 \%$ and $10 \%$, respectively, of each load in the Hotel.

The power capacity of each of the 5 PV panels installed in the Hotel is equal to $50 \mathrm{~kW}$, which results in a total power capacity of $250 \mathrm{~kW}$. Fig. 3 shows the power generation profile for the PV panels.

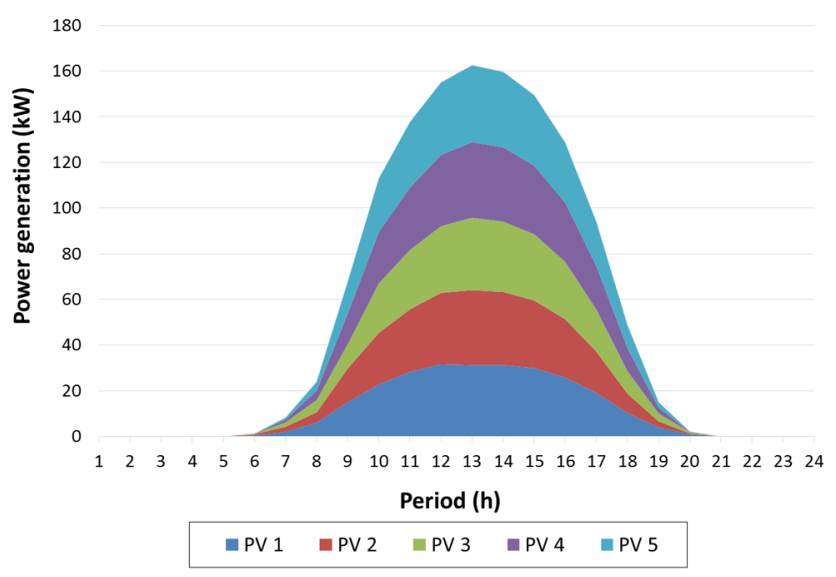

Fig. 3. Power generation profile of the PV panels.

In addition, a Combined Heat and Power (CHP) unit is also included in one of the scenarios used in this case study. The CHP unit has a power capacity of $2 \mathrm{MW}$. The DG units are not enough to supply the required demand of the Hotel, thus the aggregator requires to acquire energy from external suppliers outside of the Hotel's network. For this case study 5 different external suppliers have been used, each one has a different installed power and energy price.

A number of $150 \mathrm{EVs}$ were considered in this case study, the EVeSSi simulator tool [10] was used to generate the EVs movements and trips consumption during a day. The EVs will be parked in the hotel. Table I indicates the units, power capacity and prices for all resources used in this case study.

TABLE I. POWER AND PRICE OF EACH DER OF THE HOTEL

\begin{tabular}{|c|c|c|c|c|}
\hline \multicolumn{2}{|c|}{ Resource type } & \multirow{2}{*}{$\begin{array}{c}\text { Units } \\
5 \\
\end{array}$} & \multirow{2}{*}{$\begin{array}{c}\text { Power (kW) } \\
250\end{array}$} & \multirow{2}{*}{$\frac{\operatorname{Price}(\boldsymbol{€} / \mathbf{k W h})}{0}$} \\
\hline & PV & & & \\
\hline D & CHP & 1 & 2000 & 0.07 \\
\hline \multirow{5}{*}{$\begin{array}{l}\text { External } \\
\text { suppliers }\end{array}$} & 1 & \multirow{5}{*}{-} & 500 & 0.06 \\
\hline & 2 & & 1000 & 0.07 \\
\hline & 3 & & 1000 & 0.08 \\
\hline & 4 & & 1000 & 0.09 \\
\hline & 5 & & 1000 & 0.10 \\
\hline \multirow{2}{*}{$\begin{array}{l}\text { DR of } \\
\text { loads }\end{array}$} & Reduce & \multirow{2}{*}{41} & 870 & 0.08 \\
\hline & Cut & & 435 & 0.09 \\
\hline \multirow{2}{*}{ EV } & Charge & \multirow{2}{*}{150} & 450 & 0 \\
\hline & Discharge & & 450 & 0.06 \\
\hline
\end{tabular}

\section{B. Scenario Structure}

For this case study were developed 7 scenarios, where the first scenario is the base scenario of the hotel. The main 
purpose of this base scenario is to be used as reference for the results of the other 6 scenarios. The results of the other scenarios will be compared to the results of this scenario in order to understand the impact that the changes in the other 6 scenarios have in the management of the hotel. The description of all scenarios in this case study is presented below:

1. Scenario 1 - Base scenarios;

2. Scenario 2 - without DG;

3. Scenario 3 -decrease of Suppliers' power;

4. Scenario 4 - without DG and decrease of Suppliers' power;

5. Scenario 5 - with EVs;

6. Scenario 6 - with CHP;

7. Scenario 7 - with CHP and decrease of Suppliers' power.

In scenarios 3, 4 and 7, the energy acquired from external suppliers was reduced in $1000 \mathrm{~kW}$, namely supplier 1 does not offer and supplier 2 only can offer $500 \mathrm{~kW}$ (see Table I). The sampling period and time-horizon of all scenarios are 1 hour and 24 hours, respectively. The aggregator can supply the required demand (see Fig. 2) through the DG units (i.e. PV or CHP), external suppliers, DR programs (i.e. reduce and cut) or EVs discharge.

\section{Results and Analysis}

The ERM simulation platform solved the 7 scenarios, and Fig. 4 shows the scheduling obtained by the ERM simulation platform for three scenarios, namely scenario 1 (base), 4 and 7 . In scenario 1 (see Fig. 4 a)), the DR programs are already required by the aggregator to supply the demand of the hotel, because the aggregator does not have enough power generation from the endogenous resources (i.e. PV panels). Additionally, the DR programs, namely the DR reduce, is cheaper than the expensive external suppliers, such as suppliers 4 and 5 with a price of 0.09 and $0.1 € / \mathrm{kWh}$. The DR programs (reduce and cut) are more used from period 9 to period 18 , because the power consumption is higher between these periods.

In scenario 4 (see Fig. 4 b)), the DR programs (reduce and cut) compensated the decrease of $1000 \mathrm{~kW}$ in the suppliers' offers. The aggregator needed to use DR instead of acquiring from the expensive suppliers, such as supplier 4 and 5. The DR is fully scheduled between periods 9 and 21 . In this scenario, the DR programs reached a significant share in the ERM result of around $28 \%$. The aggregator was able to schedule the remaining power demand of the hotel through the use of DR programs, otherwise the aggregator would have to compensate the hotel $\left(c_{N S D(L, t)}\right)$ for not supplied demand.

In scenario 7 (see Fig. 4 c)), the introduction of CHP unit changes completely the scheduling when compared with the one obtained in scenario 1. In this case, the CHP is fully dispatched in all periods. Additionally, the suppliers' offers have been reduced which implied the use of more DR programs. The DR programs have a similar solution as the one obtained in scenario 1 . a)

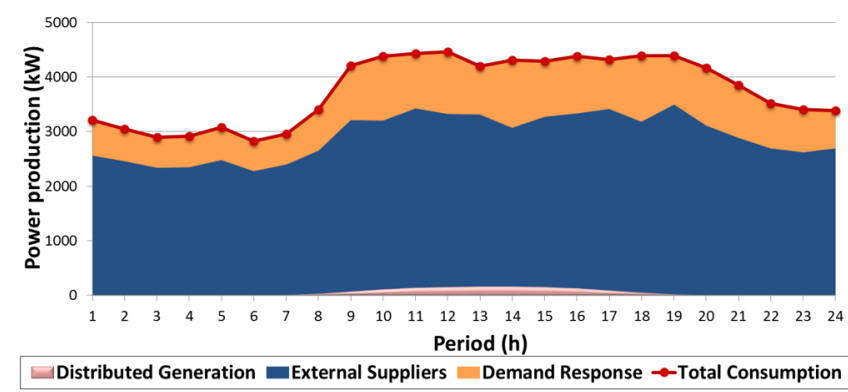

b)

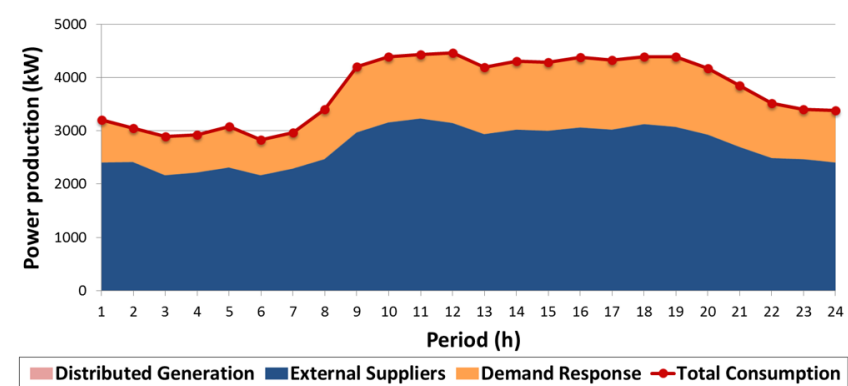

c)

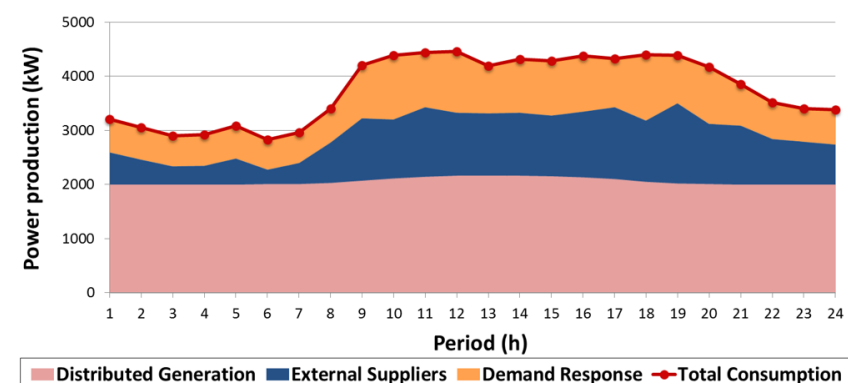

Fig. 4. ERM result: a) scenario 1 (base), b) scenario 4 and c) scenario 7.

Table II presents the cost and time obtained for each scenario of this case study. Additionally, the percentage of the cost variation between each scenario and scenario 1 (base) is also presented in the table.

TABLE II. COST AND TIME RESULTS FOR ALL SCENARIOS.

\begin{tabular}{|c|c|c|c|c|c|}
\hline \multirow{2}{*}{\multicolumn{2}{|c|}{ Scenario }} & \multicolumn{4}{|c|}{ ERM results } \\
\hline & & 1 (Base) & 2 & 3 & 4 \\
\hline \multirow{2}{*}{ Cost } & $(€)$ & 6775.73 & 6889.63 & 7425.78 & 7552.11 \\
\hline & $\%$ & - & +1.68 & +9.59 & +11.46 \\
\hline \multicolumn{2}{|c|}{ Time (s) } & 3.42 & 1.69 & 1.89 & 1.71 \\
\hline \multirow{2}{*}{\multicolumn{2}{|c|}{ Scenario }} & \multicolumn{4}{|c|}{ ERM results } \\
\hline & & 1 (Base) & 5 & 6 & 7 \\
\hline \multirow{2}{*}{ Cost } & $(€)$ & 6775.73 & 6862.07 & 6211.21 & 6698.85 \\
\hline & $\%$ & - & +1.27 & -8.33 & -1.13 \\
\hline \multicolumn{2}{|c|}{ Time (s) } & 3.42 & 3.58 & 1.75 & 1.73 \\
\hline
\end{tabular}

The scenarios 3 and 4 reached the highest values in terms of cost for the aggregator, because in both scenarios the 
suppliers' power is reduced in $1000 \mathrm{~kW}$. This reduction led the aggregator to schedule more DR programs, which are more expensive than the suppliers 1 and 2 . On the other hand, the scenario 6 achieved the lowest cost. This happen due to the introduction of a CHP unit, which is fully dispatched in most of the scheduling periods. In terms of time, all the scenarios achieved insignificant times between 1 and 3 seconds. Thus, this parameter is not as relevant as the cost for this case study.

Table III presents the comparison of the scheduling obtained for all scenarios. The scenario 1 presents the total scheduling of each resource (PV, suppliers and DR) for the day. On the other hand, in the remaining scenarios is presented the variation of the scheduling obtained in each scenario to the scenario 1 (base). The CHP and EVs were not considered in this table, because they do not appear in all scenarios. Although their results will be also discussed in this section.

TABLE III. COMPARISON OF THE SOLUTION IN ALL SCENARIOS

\begin{tabular}{|c|c|c|c|c|}
\hline \multirow{2}{*}{$\begin{array}{c}\text { Resource } \\
\text { Type }\end{array}$} & $\mathbf{1}$ (Base) & $\mathbf{2}$ & $\mathbf{3}$ & $\mathbf{4}$ \\
\cline { 2 - 5 } & $1266.63 \mathrm{~kW}$ & $-100 \%$ & 0 & $-100 \%$ \\
\hline PV panels & $68,474.09 \mathrm{~kW}$ & $+1.85 \%$ & $-6.40 \%$ & $-4.55 \%$ \\
\hline $\begin{array}{c}\text { External } \\
\text { suppliers }\end{array}$ & $20,678.61 \mathrm{~kW}$ & 0 & $+21.20 \%$ & $+21.20 \%$ \\
\hline $\begin{array}{c}\text { DR (reduce } \\
\text { and cut) }\end{array}$ & $\mathbf{1}$ (Base) & $\mathbf{5}$ & $\mathbf{6}$ & 7 \\
\hline $\begin{array}{c}\text { Resource } \\
\text { Type }\end{array}$ & $1266.63 \mathrm{~kW}$ & 0 & 0 & 0 \\
\hline \begin{tabular}{c} 
PV panels \\
\cline { 1 - 5 }
\end{tabular} & $68,474.09 \mathrm{~kW}$ & $+1.01 \%$ & $-45.74 \%$ & $-68.74 \%$ \\
\hline $\begin{array}{c}\text { External } \\
\text { suppliers }\end{array}$ & $20,678.61 \mathrm{~kW}$ & $0.90 \%$ & $-68.31 \%$ & $-4.51 \%$ \\
\hline $\begin{array}{c}\text { DR (reduce } \\
\text { and cut) }\end{array}$ & \multicolumn{4}{|c|}{ ERults } \\
\hline
\end{tabular}

As expected, the DR programs compensate the decrease of power generation in the scenarios that simulated this effect, such as scenario 2 (without DG), scenario 3 (decrease of suppliers' power) and scenario 4 (without DG and decrease of suppliers' power). In scenario 2 , the DR result is the same as scenario 1 (base). In this scenario the decrease of power generation by removing PV panels has a small impact in the scheduling. In the other scenarios (3 and 4), the DR programs increased in around $21 \%$ of their impact in the scheduling.

In scenario 5 (with EVs), the scheduling is almost the same as the base scenario, the variations between both scenarios are not relevant. The external suppliers and DR programs increased in around $1 \%$ due to the introduction of EVs charge. The last two scenarios are completely different because of the introduction of the CHP unit. This unit enables the aggregator to reduce the dispatch of external suppliers and DR programs, which are more expensive than the CHP unit. In scenario 6 (with CHP), the scheduling of external suppliers as well as DR programs are reduced around $46 \%$ and $68 \%$, respectively.

As final considerations of this case study, the main one is concerning the application of DR programs. This resource has a significant impact in the scheduling in scenarios with a low availability in terms of power generation. The DR reached a significant impact between $20 \%$ and $30 \%$, which can be seen in scenarios 1, 2, 3, 4 and 7. The intensively use of DR programs can be triggered by reducing the supplier's power, or by increasing the suppliers' price. In addition, the DR programs can be implemented in different equipment in the Hotel, such as it was explored in this case study. The decrease of consumption can be reached without causing impact in the satisfaction of the guests in their rooms. In this case study, the DR programs are not applied in the hotel's rooms. The use of DR programs can help the aggregator to effectively reduce the contracted power of the hotel with the retailer.

\section{CONCLUSIONS}

Demand response and distributed generation are playing an important role in the smart grids context, namely including buildings as part of a distribution gird with its own resources. The present paper addressed the integration of an energy resource scheduling model in a web based platform that supports the consumer decisions about the electricity consumption. The model considered the consumption reduction and the photovoltaic resources available; consumption and generation forecasts have been included. The case study shown that demand response has a significant impact in the scheduling in scenarios with a low availability in terms of power generation. Moreover, the decrease of consumption can be reached without causing impact in the satisfaction of the guests in their rooms.

\section{REFERENCES}

[1] IEA, "Transition to Sustainable Buildings - Stategies and Opportunities to $2050, " 2013$

[2] C. A. Hill, M. C. Such, D. Chen, J. Gonzalez, and W. M. Grady, "Battery energy storage for enabling integration of distributed solar power generation," IEEE Trans. Smart Grid, vol. 3, no. 2, pp. 850-857, 2012.

[3] P. Faria, Z. Vale, and J. Baptista, "Constrained consumption shifting management in the distributed energy resources scheduling considering demand response," Energy Convers. Manag., vol. 93, pp. 309-320, 2015.

[4] IEA, “Technology Roadmap - Solar Photovoltaic Energy,” 2014.

[5] M. Silva, H. Morais, T. Sousa, and Z. Vale, "Energy resources management in three distinct time horizons considering a large variation in wind power," in European Wind Energy Conference and Exhibition, EWEC 2013, 2013, vol. 2, pp. 789-797.

[6] M. Silva, H. Morais, Z. Vale, and P. Faria, "Short-term scheduling considering five-minute and hour-ahead energy resource management," in IEEE Power and Energy Society General Meeting, 2012.

[7] M. Iqbal, M. Azam, M. Naeem, A. S. Khwaja, and A. Anpalagan, "Optimization classification, algorithms and tools for renewable energy: A review," Renewable and Sustainable Energy Reviews, vol. 39. pp. 640-654, 2014.

[8] A. Y. Saber and G. K. Venayagamoorthy, "Resource scheduling under uncertainty in a smart grid with renewables and plug-in vehicles," IEEE Syst. J., vol. 6, no. 1, pp. 103-109, 2012.

[9] M. A. Islam, M. Hasanuzzaman, N. A. Rahim, A. Nahar, and M. Hosenuzzaman, "Global renewable energy-based electricity generation and smart grid system for energy security.," Sci. World J., vol. 2014, p. 197136, 2014.

[10] J. Soares, B. Canizes, C. Lobo, Z. Vale, and H. Morais, "Electric vehicle scenario simulator tool for smart grid operators," Energies, vol. 5, no. 6, pp. 1881-1899, 2012. 